\title{
Non destructive neutron diffraction measurements of cavities, inhomogeneities, and residual strain in bronzes of Ghiberti's relief from the Gates of Paradise
}

\author{
G. Festa, ${ }^{1, a)}$ R. Senesi, ${ }^{1}$ M. Alessandroni, ${ }^{1}$ C. Andreani, ${ }^{1}$ G. Vitali, ${ }^{1}$ S. Porcinai, ${ }^{2}$ \\ A. M. Giusti, ${ }^{2}$ T. Materna,${ }^{3}$ and A. M. Paradowska ${ }^{4}$ \\ ${ }^{1}$ Università degli Studi di Roma Tor Vergata, Dipartimento di Fisica and Centre NAST Via della R. Scientifica 1, \\ Rome, Italy \\ ${ }^{2}$ Opificio delle Pietre Dure, Florence, Italy \\ ${ }^{3}$ Institut Laue-Langevin 6, rue Jules Horowitz, BP 156, 38042 Grenoble Cedex 9, France \\ ${ }^{4}$ ISIS Neutron Scattering Facility-Science and Technology Facility Council, Rutherford Appleton Laboratory, \\ Harwell Science and Innovation Campus, Didcot, OX11 OQX, United Kingdom
}

(Received 15 July 2010; accepted 1 February 2011; published online 23 March 2011)

\begin{abstract}
Quantitative neutron studies of cultural heritage objects provide access to microscopic, mesoscopic, and macroscopic structures in a nondestructive manner. In this paper we present a neutron diffraction investigation of a Ghiberti Renaissance gilded bronze relief devoted to the measurement of cavities and inhomogeneities in the bulk of the sample, along with the bulk phase composition and residual strain distribution. The quantitative measurements allowed the determination of the re-melting parts extension, as well as improving current knowledge about the manufacturing process. The study provides significant and unique information to conservators and restorators about the history of the relief. (C) 2011 American Institute of Physics. [doi:10.1063/1.3560915]
\end{abstract}

\section{INTRODUCTION}

The gilded bronze relief under investigation is part of the east monumental door located at the Battistero di Firenze, manufactured by Lorenzo Ghiberti between 1425 and 1452. The doors are one of the greatest masterpieces of the Florentine Renaissance and are of particular important because during the 15th Century Michelangelo gave them the name by which they are still known today: The Gates of Paradise. They represented, indeed, a milestone in sculpture which influenced generations of artists in Europe. The Gates of Paradise include a total of about 48 gilded bronze frame pieces surrounding the main panels. During the twenty-yearlong restoration at the Opificio delle Pietre Dure (OPD) Laboratories, the panels have been extensively investigated with standard techniques (SEM/EDS, Auger, XRF, etc.) ${ }^{1-4}$ in order to study the manufacturing processes and the conservation state, e.g., the alloy composition and the main alteration processes which have damaged the mercury gilding. At the present time the restoration of the Gates of Paradise is reaching its final stage. The gilded relief will be re-mounted into the bronze frame and on display to the public.

This paper presents a nondestructive neutron diffraction investigation of a gilded bronze frame piece depicting a prophet head (Fig. 1) which was made by applying the lostwax casting method. This was a well known casting process in the Renaissance period which consists of pouring melted metals into the space formerly occupied by the wax layers.

Thermal neutrons have a high penetration power (penetration power of the order of centimeters within the bulk of the bronze) and give bulk information without any sampling

\footnotetext{
a) Author to whom correspondence should be addressed. Electronic mail: giulia.festa@roma2.infn.it.
}

or damage. Previous works ${ }^{5-7}$ have demonstrated the effectiveness of neutron diffraction techniques applied to the study of archaeological and artistic objects. There are no other methods available which are nondestructive and able

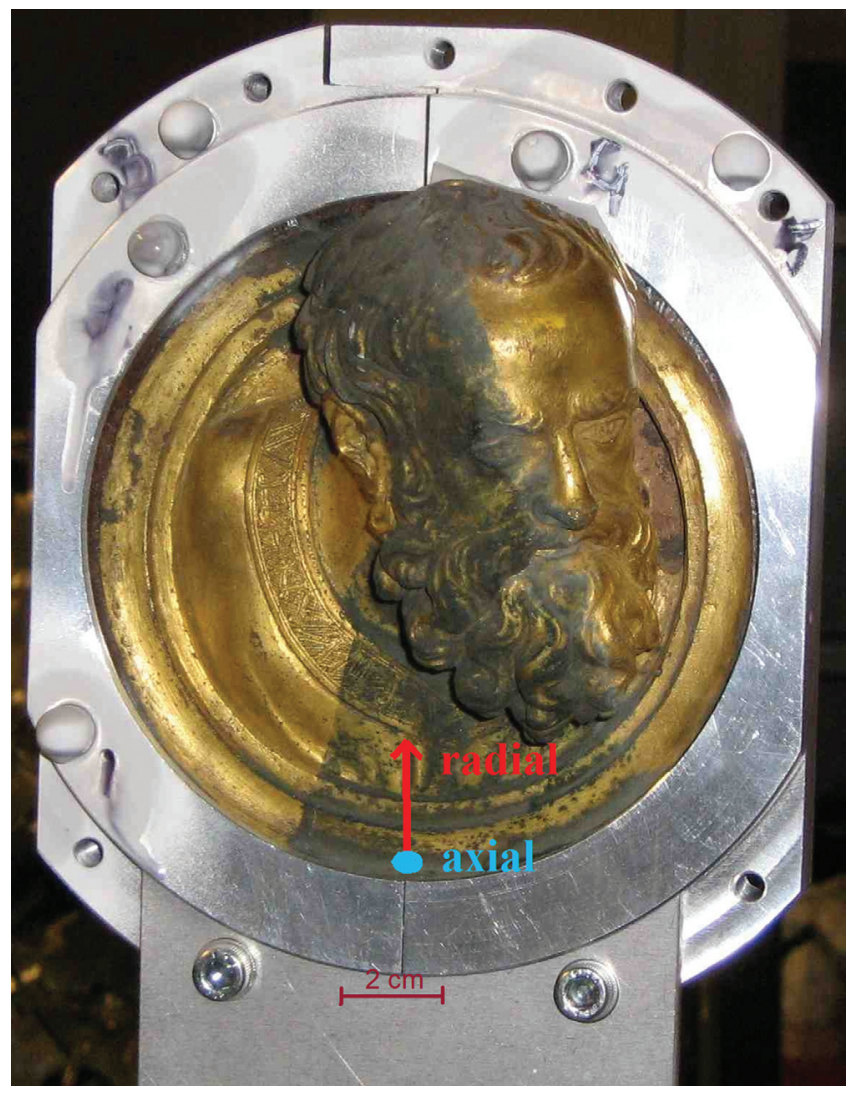

FIG. 1. (Color online) Gilded relief in its own sample holder. It has a diameter of $13 \mathrm{~cm}$, a height of $7 \mathrm{~cm}$ and a mass of $2700 \mathrm{~g}$. Strain directions (radial and axial) are reported in the figure. 
to give information about the bulk properties of such artifacts.

The aim of the present study was to perform a characterization of the bulk phase composition and residual strain distribution in small areas at critical locations. Moreover, the object under examination presents a re-melting in the lower part. This is probably a repair due to possible defects that occurred during the primary casting. Previous investigation using the neutron radiography method $^{8}$ revealed a lighter area in the images. This fact supported the hypothesis that there is a cavity or a region with unknown inhomogeneous material, for example, clay. The present measurements help to answer this intriguing question.

Neutron diffraction measurements were carried out at the ISIS Rutherford Appleton Laboratory using the ENGIN-X instrument. The final results provide valuable information regarding the history and manufacturing process of this anomalous piece of craftsmanship.

\section{EXPERIMENT}

Measurements were carried out at the ENGIN-X diffractometer, ISIS neutron facility (U.K.). The beam-line was successfully used to investigate various structures of archaeological samples. ${ }^{8-10}$ Neutron diffraction provides information on the crystalline phase composition of the alloy, the microstructure, strains, and the crystallographic texture, all of which can be related to the manufacturing and working conditions of the investigated object.

The engineering diffractometer at ISIS, ENGIN-X ${ }^{11,12}$ has its flux distribution peaked around a neutron wavelength of $2 \AA$. The sample position is at $50.0 \mathrm{~m}$ from the moderator. The instrument uses a $33.5 \mathrm{~m}$ long curved super-mirror guide followed by a $10.5 \mathrm{~m}$ long straight guide, ending $1.5 \mathrm{~m}$ before the sample position. For the measurements on the prophet head, the instrument was operated at an effective 17 and $25 \mathrm{~Hz}$ frequency running, using two sets of counterrotating disk choppers to avoid frame overlap. The corresponding measurement frame was $40 \mathrm{~ms}$ between two successive neutron pulses. The time delay of the chopper openings with respect to the neutron generation at 'timezero' determines the neutron wavelength band that can pass through to the sample, and thus determines the associated d-spacing range. This time delay was set for a d-spacing range from $0.88-3.50 \AA$ and $0.21-2.7 \AA$, respectively, to include the characteristic Bragg peak positions of the relevant crystallographic phases.

Scattered neutrons are recorded in two $90^{\circ}$-detector banks, on either side of the sample position and positioned at a distance of $1.5 \mathrm{~m}$ from the sample. The detectors measure the time of flight (TOF) of each detected neutron, that is, the time that passes from the generation of the neutron until its capture in the detector. On ENGIN-X, one can define a small measurement volume (gauge volume) in the sample on the order of a few cubic millimeters. This is achieved by collimating the incident beam (width $\times$ height), and by using a radial collimator in front of the detectors to accept only neutrons from a certain depth along the incident beam direction (Fig. 2). Hence the diffraction pattern only contains neutrons

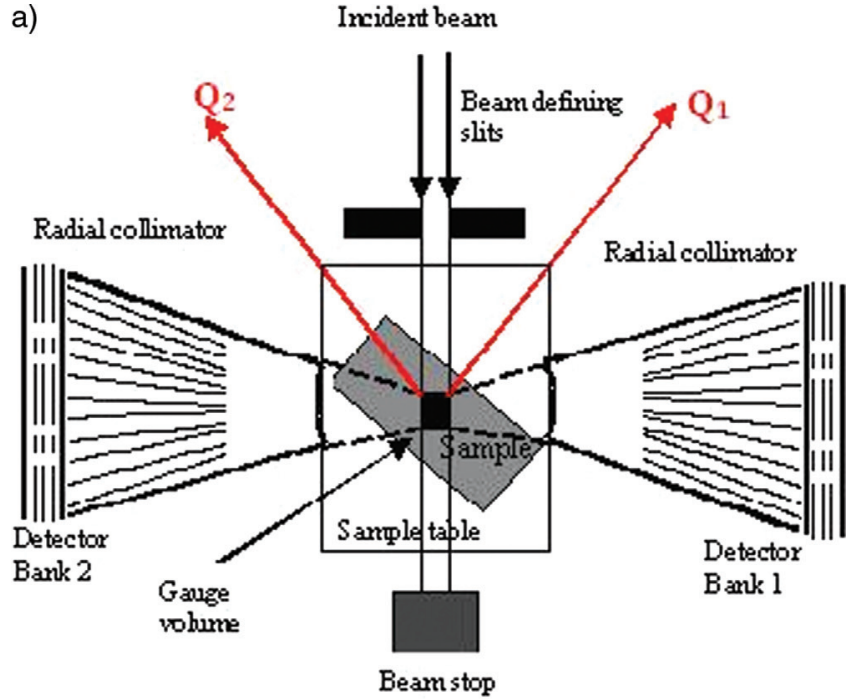

b)

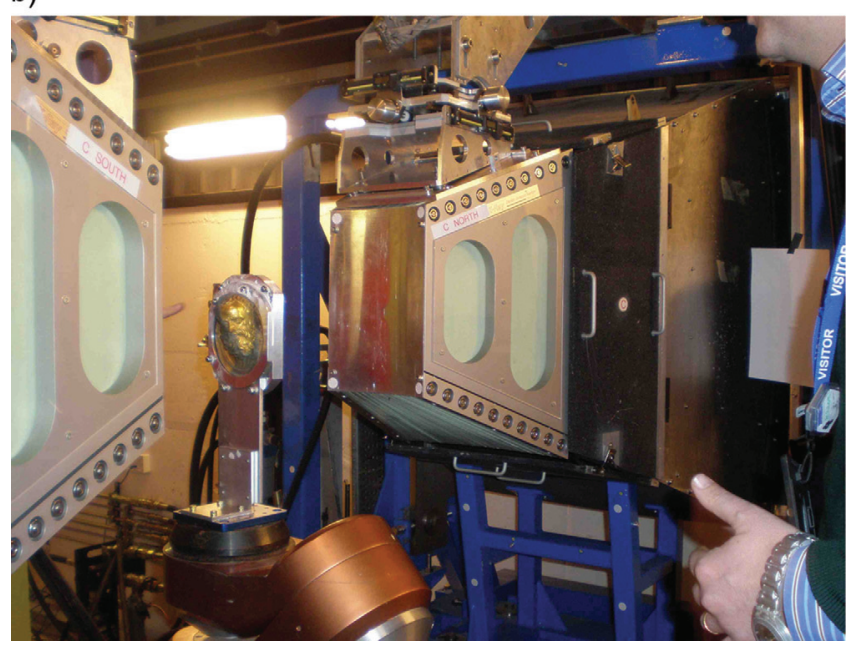

FIG. 2. (Color online) ENGIN-X instrument at ISIS spallation neutron source (Chilton, Oxfordshire, UK). (a) Schematic view of the experimental set-up where $\mathrm{Q}_{1}$ and $\mathrm{Q}_{2}$ denote the scattering vectors of the measurements; (b) overview of positioning of the object during the experiment.

scattered from the gauge volume which can be fully immersed in the sample. The experimental gauge volume is defined by the geometry of the incident primary slits and the collimators. In this investigation the incident primary slit was set to $2 \times 2 \mathrm{~mm}^{2}$ and $2 \mathrm{~mm}$ radial collimators were used to create the gauge volume of $2 \times 2 \times 2 \mathrm{~mm}^{3}$. The distance of the primary slits from the measurement locations were 40 $\mathrm{mm}$ and were constant through all the experiments. The sample can be systematically scanned in front of the neutron beam, by which we mean that the gauge volume is scanned through the sample.

For a neutron source with neutron-flux time structure (as in the case of pulsed sources like ISIS) what is measured is the TOF. From the TOF it is possible to determine neutron velocity and therefore, its wavelength. The well known Bragg's law can thus be re-written as a relation between the TOF of neutrons scattered from a set of planes in the sample and the spacing between these planes, $\mathrm{d}_{h k l}$ as

$$
(\mathrm{TOF})_{h k l}=\left(2 m_{\mathrm{n}} / h\right) L \mathrm{~d}_{h k l} \sin \theta_{0},
$$




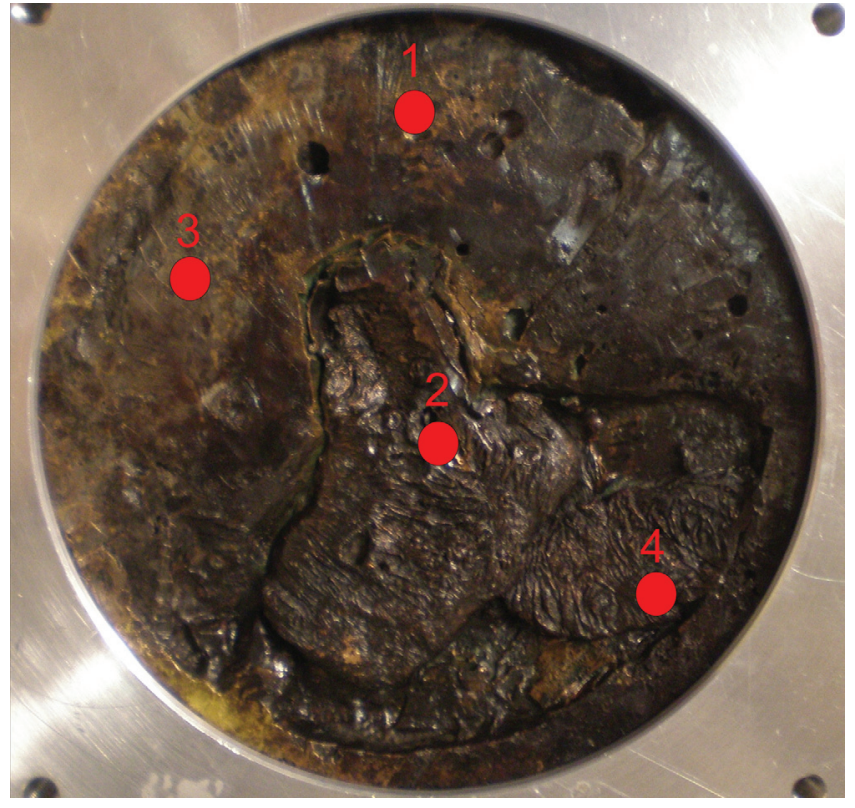

FIG. 3. (Color online) Back side of the relief with measurement points for phase composition determination. Points 1 and 3 are positioned in the primary melting zone while points 2 and 4 are positioned in the re-melting volume.

where $\mathrm{m}_{\mathrm{n}}$ is the neutron mass, $L$ is the flight length of the pulsed beam from the moderator to the sample, and $\theta_{0}$ is the fixed scattering angle.

To optimize experiments, ENGIN-X is equipped with two laser scanning inspection arms, a robotic arm, and virtual laboratory software. This precise coordinate measurement set-up enables the definition of the measurement points inside the sample with high precision (on the order of $10 \mu \mathrm{m})$ and plan the diffraction scans in advance. The gilded bronze head was scanned using the laser arm and the virtual model was created as input for the dedicated virtual laboratory simulation software, known as SScanSS..$^{13}$ The SScanSS software was used to identify the measurement points inside the laser model of the head and it produced the $\mathrm{x}, \mathrm{y}$, and $\mathrm{z}$ coordinate values of these points with respect to the reference system of the instrument. The resulting coordinate file is readable from the instrument software which automati-

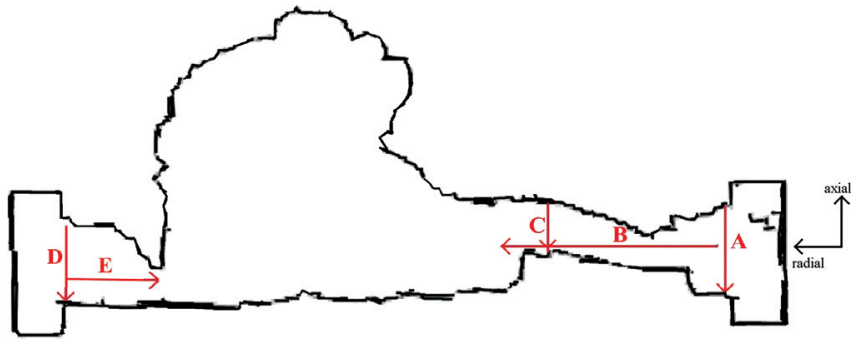

FIG. 4. (Color online) Cross section view of the laser scan surface of the relief. Diffraction scans loci are reported. Inside the re-melting: $\mathrm{A}=$ vertical scan, $\mathrm{B}=$ horizontal scan, and $\mathrm{C}=$ internal vertical scan. Inside the primary melting: $\mathrm{D}=$ vertical scan and $\mathrm{E}=$ horizontal scan. The first points of scans $\mathrm{A}, \mathrm{C}$, and D were located $5 \mathrm{~mm}$ from the surface and the distance between points in a scan is $5 \mathrm{~mm}$. The first points of scans B and E were located 10 and $15 \mathrm{~mm}$, respectively, from the surface and distance between points in a scan is $5 \mathrm{~mm}$.

cally performs measurement scans. In the case of complex object shapes, such as this one, the possibility of identifying the measurement points with high precision was crucial. The software is very well suited for efficiently planning experiments on such complex shapes. Calculation of the path length is also available in SScanSS and this allowed us to account for beam attenuation effects in order to decide measurement times and prioritize experimental procedures.

The TOF data were normalized by the incoming flux distribution. Two diffraction patterns, one for each 90-degree detector bank, were generated from the TOF data. However in the case where the neutron path-length was too large and the beam was fully attenuated only one pattern was generated by one of the detector banks. This data was simultaneously analyzed through the Rietveld method with the general structure analysis system ${ }^{14}$ (which is used by the Open Genie calculation routine available on ENGIN-X).

\section{EXPERIMENTAL PROCEDURES}

The first set of measurements were performed on the back area of the relief in order to analyze the differences in peak position and the shape between the first and second melting. Four points were chosen (Fig. 3): two in the primary fusion and two in the re-melting zone. For these

TABLE I. Results of neutron diffraction analysis performed in the back area of the relief, aiming at the phase composition. Four peak shapes are analyzed in the four points reported in Fig. 3. The table reports the d-spacing value and the $\Delta \mathrm{d} / \mathrm{d}$ ratio.

\begin{tabular}{|c|c|c|c|c|}
\hline \multicolumn{5}{|c|}{ d-spacing $(\AA)$} \\
\hline Peaks & 311 & 220 & 200 & 111 \\
\hline Point 1 & $1.09536 \pm 0.00003$ & $1.28418 \pm 0.00004$ & $1.81553 \pm 0.00004$ & $2.09581 \pm 0.00006$ \\
\hline Point 2 & $1.09491 \pm 0.00005$ & $1.28370 \pm 0.00005$ & $1.81506 \pm 0.00005$ & $2.09607 \pm 0.00005$ \\
\hline Point 3 & $1.09545 \pm 0.00002$ & $1.28425 \pm 0.00003$ & $1.81544 \pm 0.00003$ & $2.09560 \pm 0.00003$ \\
\hline Point 4 & $1.09544 \pm 0.00002$ & $1.28428 \pm 0.00003$ & $1.81561 \pm 0.00003$ & $2.09624 \pm 0.00003$ \\
\hline \multicolumn{5}{|c|}{$\Delta \mathrm{d} / \mathrm{d}$} \\
\hline & 311 & 220 & 200 & 111 \\
\hline Point 1 & $0.00157 \pm 0.00008$ & $0.00192 \pm 0.00009$ & $0.00345 \pm 0.00007$ & $0.00427 \pm 0.00009$ \\
\hline Point 2 & $0.00267 \pm 0.00014$ & $0.00326 \pm 0.00012$ & $0.00501 \pm 0.00008$ & $0.00624 \pm 0.00007$ \\
\hline Point 3 & $0.00145 \pm 0.00005$ & $0.00180 \pm 0.00007$ & $0.00314 \pm 0.00005$ & $0.00401 \pm 0.00004$ \\
\hline Point 4 & $0.00173 \pm 0.00006$ & $0.00226 \pm 0.00007$ & $0.00366 \pm 0.00005$ & $0.00456 \pm 0.00004$ \\
\hline
\end{tabular}


measurements the instrument choppers were set to operate in an effective $17 \mathrm{~Hz}$ frequency which allowed the measurement windows to be set at a d-spacing of 0.88-3.50 $\AA$. This range contains four bronze $\alpha$-phase diffraction peaks positioned at a d-spacing of 2.1,1.8,1.3, and $1.1 \AA$ generated by the corresponding family of crystallographic planes (200), (111), (220), and (311). All measurements were performed at the same depth of $1 \mathrm{~mm}$ from the surface inside the object.

A second set of measurements was devoted to the identification of the cavity or the inhomogeneous zone inside the head located in the region of the nape. Neutron diffraction spectra were used in a nonconventional way to test the absence of bronze $\alpha$ phase peaks. This denotes a bronze-free volume in the measured point. In order to increase the sensitivity of the measurement to detect different polycrystalline materials and structures or spectral contributions of incoherent scattering from amorphous materials, the adequate d-spacing range was extended.

In this investigation in particular, the frequency was increased to $25 \mathrm{~Hz}$ to define the d-spacing window between 0.21 and $2.7 \AA$, to enable any potential peaks of clays used during the casting of the artwork to be visible in the pattern.
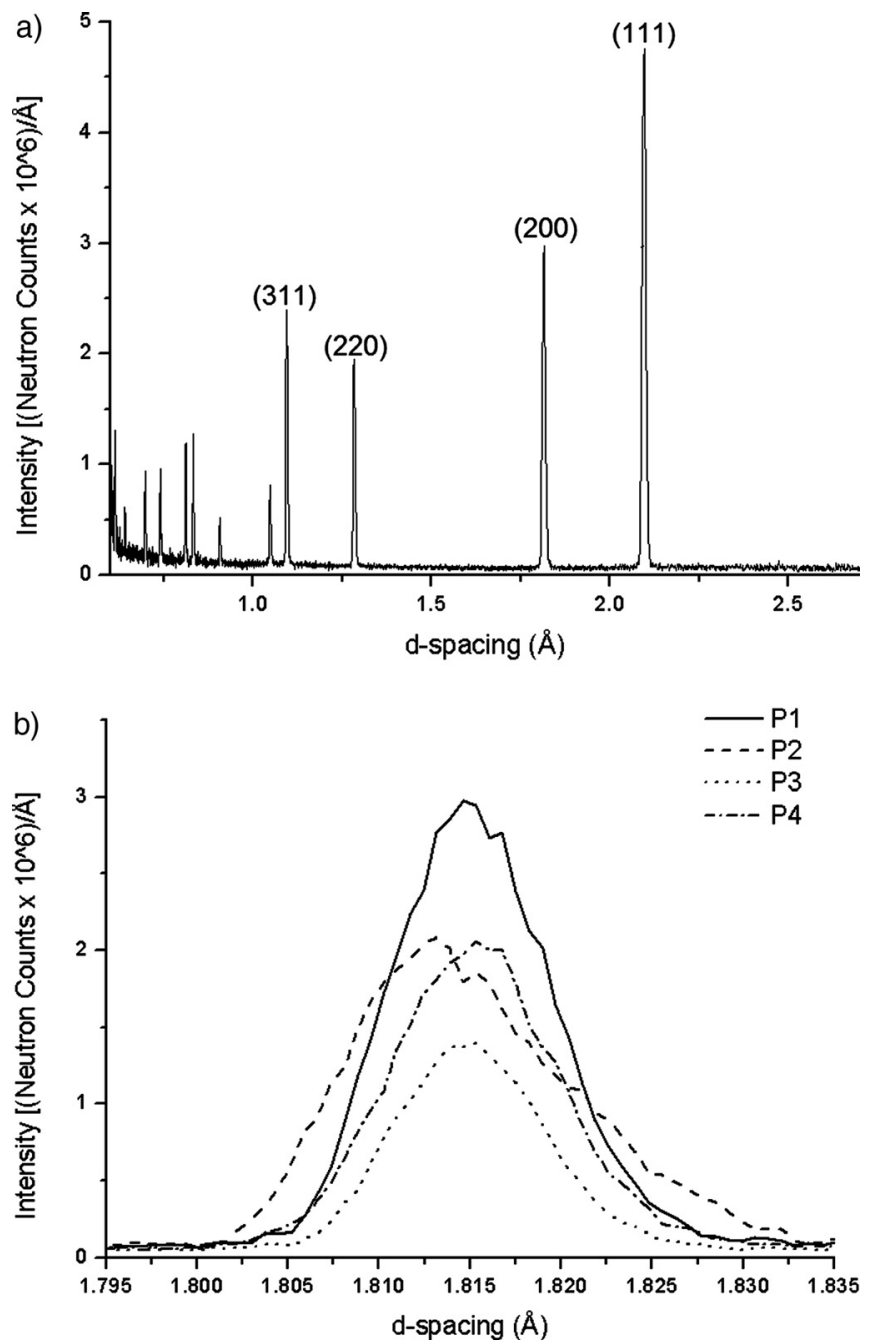

FIG. 5. Diffraction patterns of the gilded relief: (a) complete diffraction pattern; bronze peaks are visible. (b) Comparison of the (200) bronze peakshape for the measurement points (Point $1=\mathrm{P} 1$, Point $2=\mathrm{P} 2$, Point $3=\mathrm{P} 3$, Point $4=$ P4) in Fig. 3.
Measurement points inside the head were identified on the laser 3D model; the scan was made of 50 points located three-dimensionally along a grid with a spacing of $5 \mathrm{~mm}$. The relief is very thick and the diffracted neutron beam could be partially or fully absorbed. To remedy to this fact, SScanSS software was used as a measurement simulator. The software can calculate the flight path of the incident and diffracted beams inside the relief. The software tool was used to decide the best orientation of the sample to measure interesting points with the smallest neutron path length for the incident and reflected neutron beams inside the relief. Only patterns from bank 2 were used for these measurements. After these scans two points were identified in a hollow area and longer measurements were performed at $17 \mathrm{~Hz}$ to allow a large d-spacing range, between $0.88-3.0 \AA$, with the aim of observing some low amount of possible unknown materials.

A series of spatially resolved strain measurements were accomplished. Scans were performed along the vertical and horizontal directions as shown in Fig. 4, to study the bronze peak-broadening and its strain trends. Scans A, B, and C are presumably located in the re-melting zone while scans D and $\mathrm{E}$ are located in the primary melting area.

The same kind of measurement was also performed in the face zone along the beard and the face ([Fig. 9(a)], with the aim of comparing the strain trend. In fact, the conservators had hypothesized that the region of the beard could be part of the re-melting. These measurements are sub-superficial with a depth of $5 \mathrm{~mm}$ from the surface.

Indeed, different temperatures and cooling rates suffered by the re-melting alloy with respect to primary melting may have resulted in different phase compositions or differences in residual stress displayed by different strain trends.

\section{RESULTS AND DISCUSSION}

Due to the fact that, in this case, no reference samples are present all results are relative. The strain was defined in Eq. 2, as the ratio.

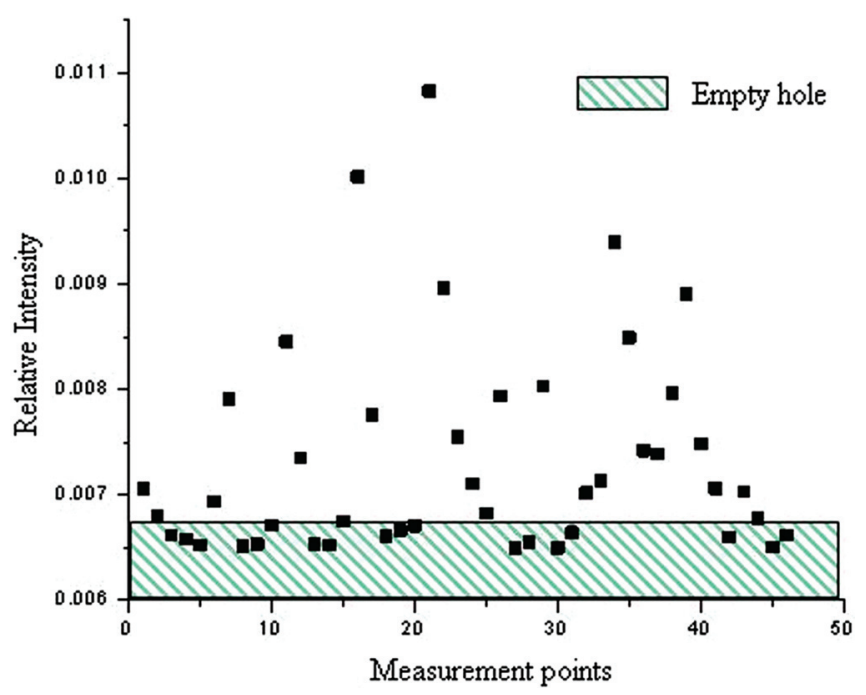

FIG. 6. (Color online) Intensity as a function of measurement points labels [reported in Fig. 7(c)] of the cavity scan for bank 2. Measurements were performed along directions parallel to the head plate starting $10 \mathrm{~mm}$ below the surface. The number of measurement $\mathrm{N}$ is the progressive number of the diffraction measurement point starting from the direction near the surface. 


$$
\varepsilon_{h k l}=\left(\mathrm{d}-\mathrm{d}_{0}\right) / \mathrm{d}_{0},
$$

where $d_{0}$ is the center of the peak in d-spacing of the unstressed material while $\mathrm{d}$ is related to the same material subjected to the stress force.

In the present work we do not have the unstressed sample to obtain the $d_{0}$ reference value as this will usually require the destructive cutting of the sample. It is not unusual that if extraction of the reference sample is not possible, the point closeest to the corner of the sample (with at least two surfaces practically relieved of stress) is used for the calculation.

In these cases, the value from a point located at the edge of the sample on the surface was used for all strain calculations. In our case the reference points are $\mathrm{N}=1$ of scan $\mathrm{A}$ for scans $\mathrm{A}, \mathrm{B}$, and $\mathrm{C} ; \mathrm{N}=1$ of scan $\mathrm{D}$ for scans D and $\mathrm{E}$. All measurements were performed at the same conditions to enable a direct comparison between the scans.

1) Results from the back area of the relief are reported in Table I. The d-spacing values and $\Delta \mathrm{d} / \mathrm{d}$ ratios of four measurement points are shown. The analysis revealed that the same peaks of the bronze $\alpha$-phase vary in the $d$-spacing and the peak width; this fact could be the result of a difference in the chemical composition and/or in the heat treatment of the two alloys.

Differences were observed in the peak-shape: as an example, the (200) $\alpha$-phase bronze peaks are reported in Fig. 5(b) with a diffraction pattern shown in Fig. 5(a). The peak shape chosen from point 2 in the re-melting area is quite different from the others. Point 4 is also located in the re-melting area and has a similar peak shape to points 1 and 3 placed in the primary melting. This could be due to the fact that point 4 is very close to the primary melting zone and the re-melting is located only on the surface. This also shows that the gauge volume is mainly located at the primary fusion. It can be said that the re-melting measurements were characterized by broader and irregular reflection peaks. Looking at the $\Delta \mathrm{d} / \mathrm{d}$ ratios of point 2 peaks (Table I), shows that they appear to be bigger compared to the others. These effects are due to dendritic segregation ${ }^{15}$ that is typical of an as-cast alloy and the higher cooling rate. This shows that the re-melting seems to be only a filler material without any treatment.

Primary melting measurements were instead characterized by regular reflection peaks. This could be related to a)

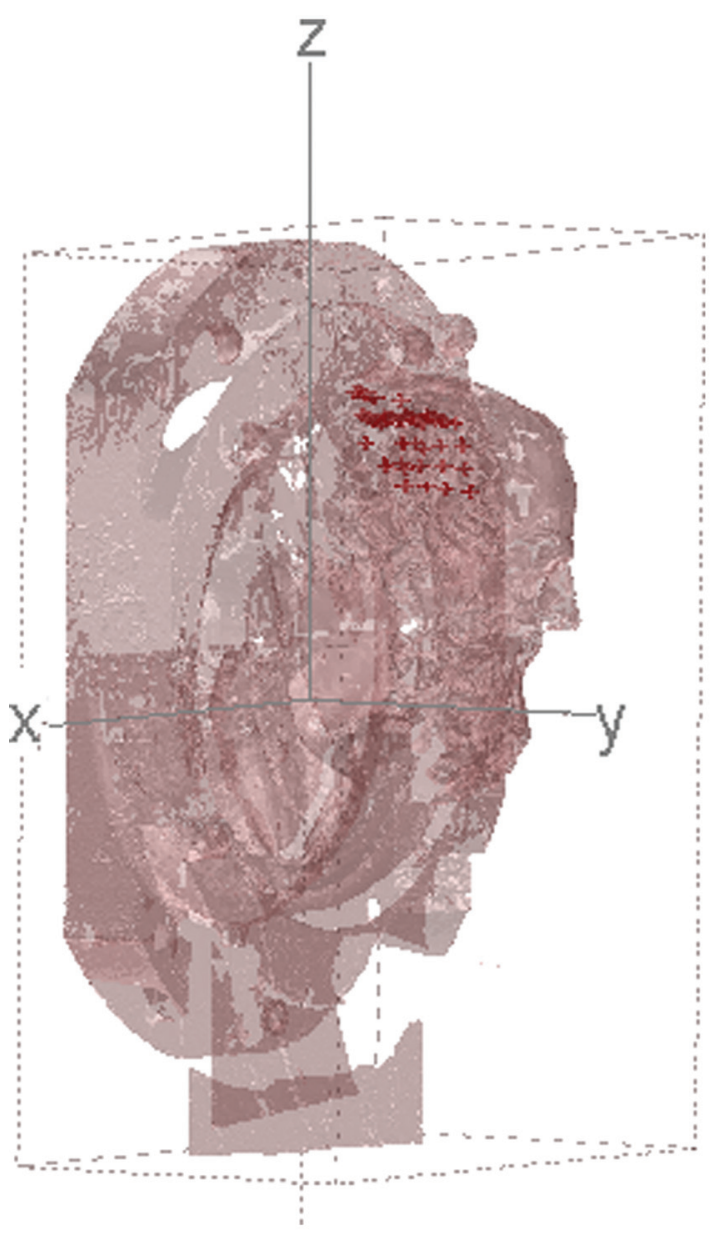

b)

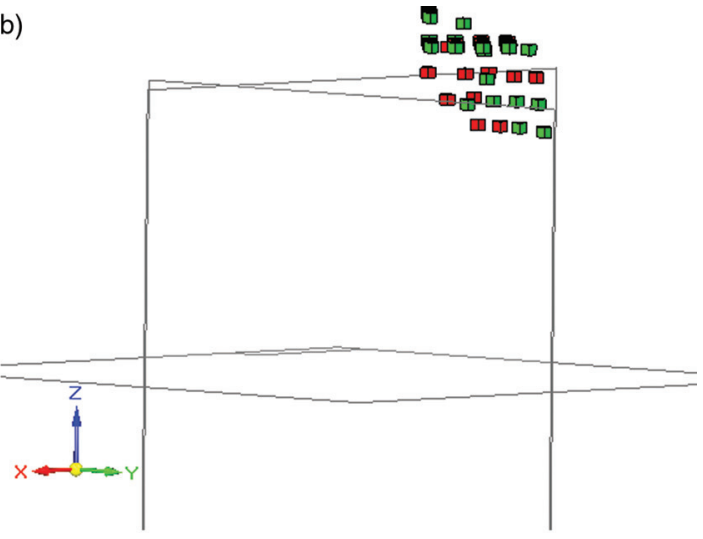

c)

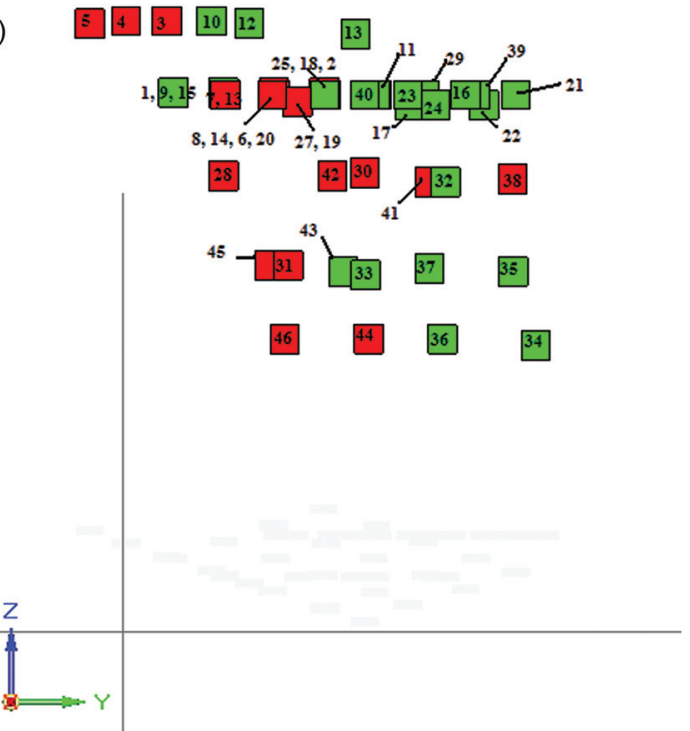

FIG. 7. (Color online) Representation of the hole inside the bronze relief: (a) 3D view of measurement points inside the bronze relief, (b) 3D view of the measurement points (red = filled, corresponding to the relative bronze peak intensity above 0.0067 , green = hollow, corresponding to the relative bronze peak intensity below 0.0067 ), and (c) 2D view on the yz plane with measurement point labels. 
other heat treatments, such as annealing and re-crystallization processes in the primary cast which are indicative of a homogenization process.

2) Signals from different parts of the nape area have been compared in order to identify some other compounds inside, and the dimension of the cavity. Measurements were performed along directions parallel to the head plate starting $10 \mathrm{~mm}$ below the surface. Figure 6 reports the intensity of the (200) $\alpha$-phase bronze peak as a function of the measurement points. We stress that in TOF neutron diffraction the signal is recorded as a multiple peak pattern and in this case has been carried out extending the d-spacing range on the whole available spectrum to identify any material possibly present in the probed volume. However, we did not find any measurable diffraction intensity nor an increase in the incoherent scattering due to the presence of amorphous content. It is therefore possible to conclude that the prophet head has a region that does not contain a-bronze or other materials like wax.

Only $\alpha$-phase bronze peaks were also observed from the long time measurements. Results showed the 3D spatial distribution of the hollow volume (Fig. 7) and excluded the presence of casting core materials like clays.

a)
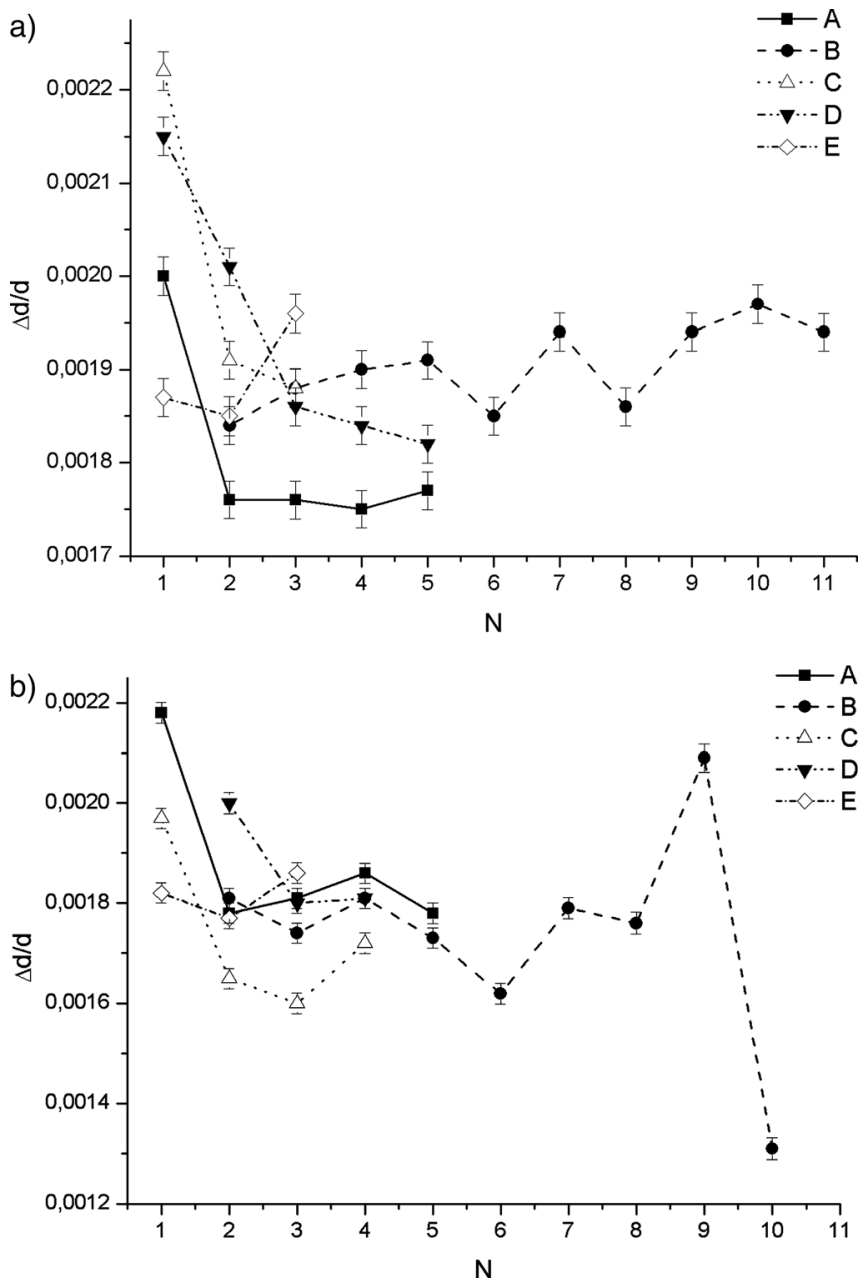

FIG. 8. $\Delta \mathrm{d} / \mathrm{d}$ trend as a function of the measurement point index $(\mathrm{N})$ along the different scans A-E. The analyzed peak is the (200) bronze reflection along (a) $\mathrm{Q}_{1}$ and (b) $\mathrm{Q}_{2}$
Diffraction scans were analyzed to obtain peak-broadening (full width at half maxima (FWHM)) and strain. Nonlinear least-square fitting of the diffraction peak's line-shape was carried out for the $\alpha$-copper reflection (111) and (200), respectively, through standard analysis routines available on the instrument. ${ }^{11,12}$ For each reflection the fitting parameters relevant for the present study, i.e., the peak centroid and the FWHM, were determined. The uncertainties on the above parameters were determined by the elements in the covariance matrix given by the fitting routines.

The trends of the $\Delta \mathrm{d} / \mathrm{d}$ ratio of peak (200), with $\Delta \mathrm{d}$ defined as the FWHM of the distribution and $\mathrm{d}$ is the medium value of it obtained by A, B, C, D, E diffraction scans, were
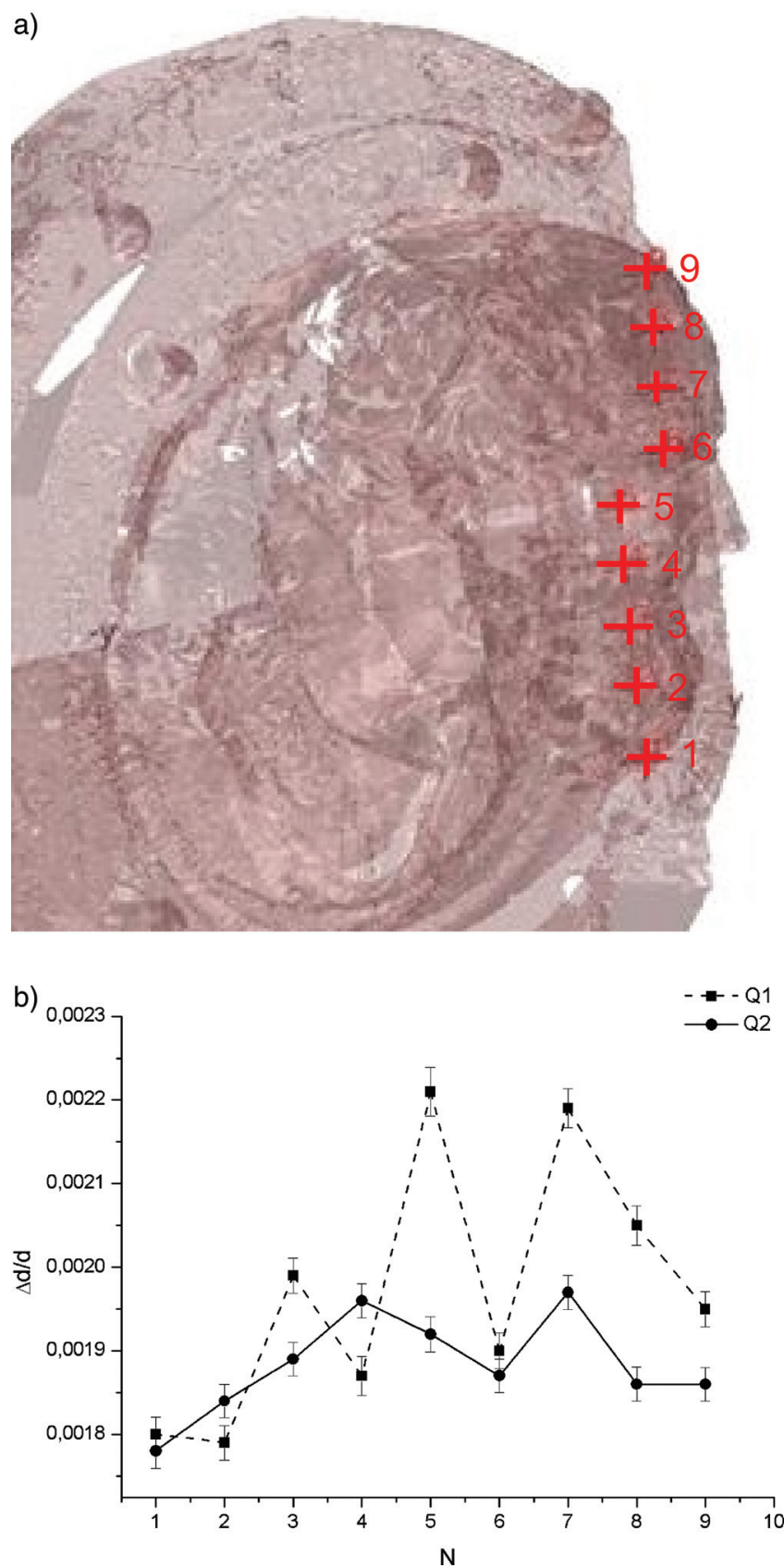

FIG. 9. (Color online) Picture of the measurement points for the beard scan and the related $\Delta \mathrm{d} / \mathrm{d}$ trend, as a function of the measurement point index $(\mathrm{N})$ of the (200) bronze peak for the (a) $\mathrm{Q}_{1}$ and (b) $\mathrm{Q}_{2}$ directions. The scan was performed with a depth of $5 \mathrm{~mm}$ from the surface. 

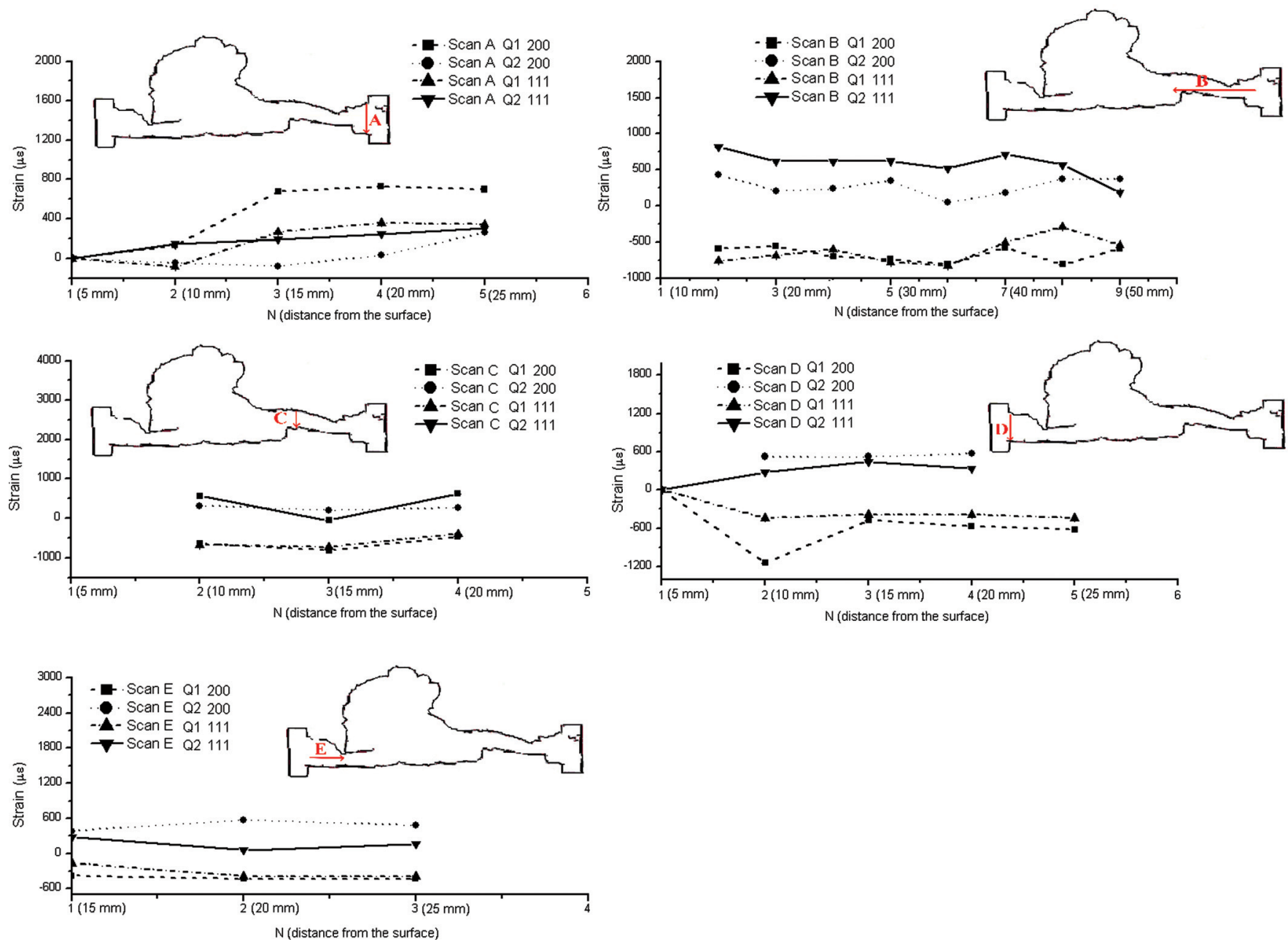

FIG. 10. (Color online) Strain plots for the (200) and (111) $\alpha$-phase bronze peaks as a function of the measurement point index (N) and the distance from the surface (in parenthesis). The strain is shown from the $\mathrm{Q}_{1}$ and $\mathrm{Q}_{2}$ directions along the A-E scans. The strain is defined as $\mu \varepsilon=\left(\mathrm{d}-\mathrm{d}_{0} / \mathrm{d}_{0}\right) \times 10^{-6}$. The reference points are $\mathrm{N}=1$ of scan $\mathrm{A}$ for scans $\mathrm{A}, \mathrm{B}$, and $\mathrm{C} ; \mathrm{N}=1$ of scan $\mathrm{D}$ for scans $\mathrm{D}$ and $\mathrm{E}$. The error bars are also reported but they are smaller than the symbol size.

compared in Fig. 8. Vertical scans have similar trends. The points are placed at $5 \mathrm{~mm}$ apart. The horizontal scan (B) presents differences in the $\Delta \mathrm{d} / \mathrm{d}$ ratio recorded by the two measurement directions $\left(\mathrm{Q}_{1}, \mathrm{Q}_{2}\right)$. This could be explained by a broadening due to a micro-strain. Points $\mathrm{N}=9$ and $\mathrm{N}=10$ in the $\mathrm{Q}_{2}$ direction [Fig. 8(b)] have a higher and lower strain value compared with other points of the same plot which can also be explained as micro-strain effects.

The trend of the $\Delta \mathrm{d} / \mathrm{d}$ ratio of peak (200) recorded in the $\mathrm{Q}_{1}$ and $\mathrm{Q}_{2}$ directions along the bear and the face is reported in Fig. 9(b). These values have a large spread and it is not possible to identify two distinct trends from $\mathrm{N}=1$ to $\mathrm{N}=5$ and from $\mathrm{N}=6$ to $\mathrm{N}=9$. This means that all of the face seems to be produced by the same casting. The variation of peak-broadening is similar with the strain variation of the re-melting scans [scan B in Figs. 8(a) and 8(b)];) this shows that the bear and face area is part of the re-melting. Strain effects could also be produced during manufacture and cold working by using tools such as chisels and other instruments. Comparing the $\Delta \mathrm{d} / \mathrm{d}$ ratio of peak (200) obtained for the face-bear scan with the $\Delta \mathrm{d} / \mathrm{d}$ trend for the re-melting and primary melting (Fig. 8), it was observed that the face-bear has a similar re-melting range of values. This could be due to the fact that the bear and face zones are part of the re-melting.

Comparison between the strain trends for the (200) and (111) $\alpha$-phase bronze peaks in the case of the re-melting (scans A, B, C in Fig. 4) and the primary melting (scans D and $\mathrm{E}$ in Fig. 4) are presented in Fig. 10. Axial and radial strain directions were conventionally defined as shown in Figs. 1 and 4. The results could be summarized as follows: along the axis of the cylinder-shaped base a widening of crystal planes is present while along the radius a compression of the plains is present. Widening and compression have the same magnitude. The re-melting scans have a larger strain variation that can be related to the absence of some homogenization process. Relative FWHM plots for the (200) and (111) $\alpha$-phase bronze peaks in the case of the re-melting and the primary melting are reported (Fig. 11). This parameter is much more diversified in the case of the re-melting compared with the primary melting. This fact confirms the differences in treatments: re-melting is only a cast while the primary melting has some successful homogenization treatments. Analysis of diffraction scans along the beard and the face show that this area is highly strain-inhomogeneous: in some areas crystal planes show a widening and in others a 

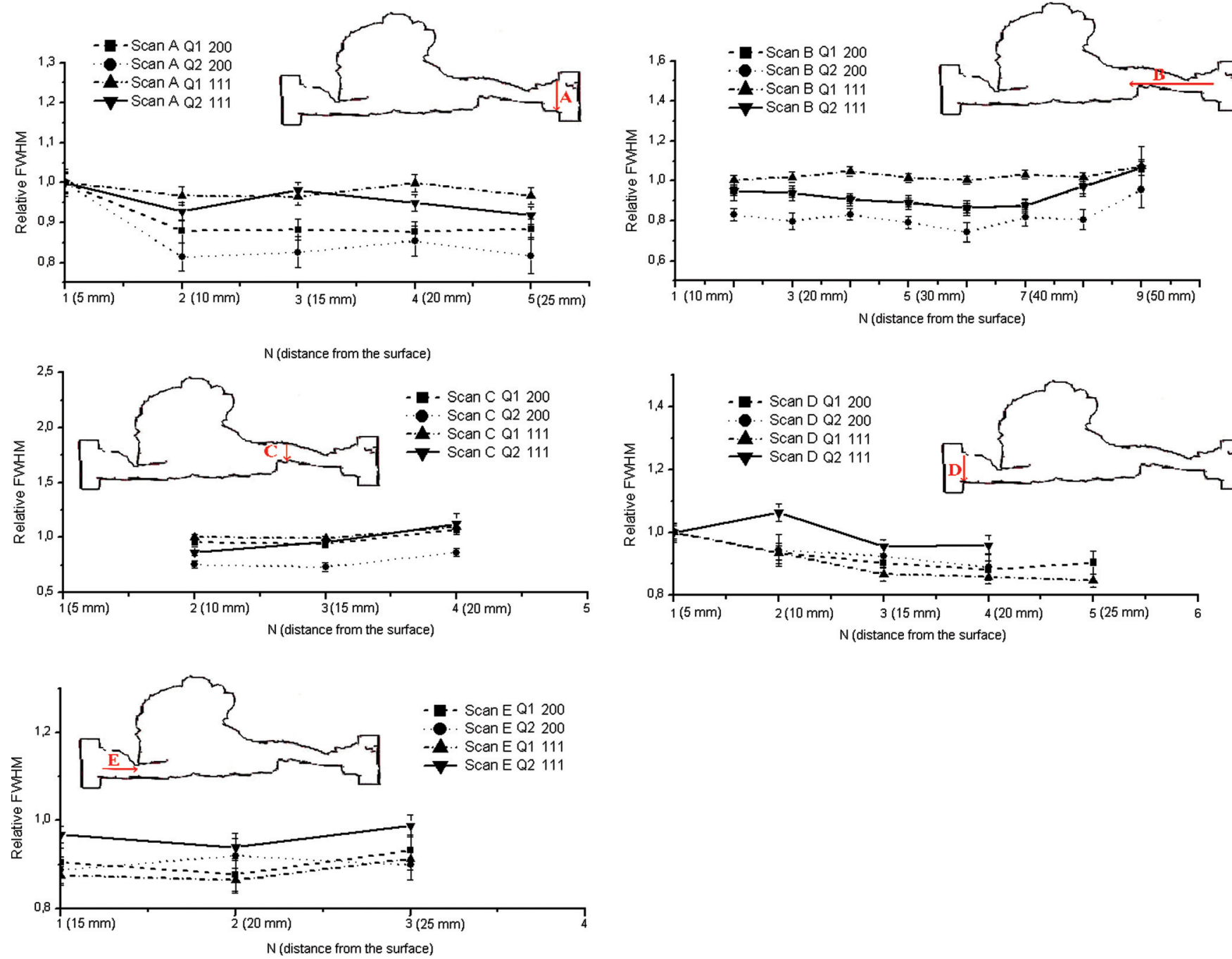

FIG. 11. (Color online) Relative FWHM plots for the (200) and (111) $\alpha$-phase bronze peaks, as a function of the measurement point index (N) and the distance from the surface (in parenthesis), shown for the $\mathrm{Q}_{1}$ and $\mathrm{Q}_{2}$ directions along the $\mathrm{A}-\mathrm{E}$ scans FWHMs are normalized to the value of the measurement considered as reference; the reference points are $\mathrm{N}=1$ of scan $\mathrm{A}$ for scans $\mathrm{A}, \mathrm{B}$, and $\mathrm{C} ; \mathrm{N}=1$ of scan $\mathrm{D}$ for scans $\mathrm{D}$ and $\mathrm{E}$.

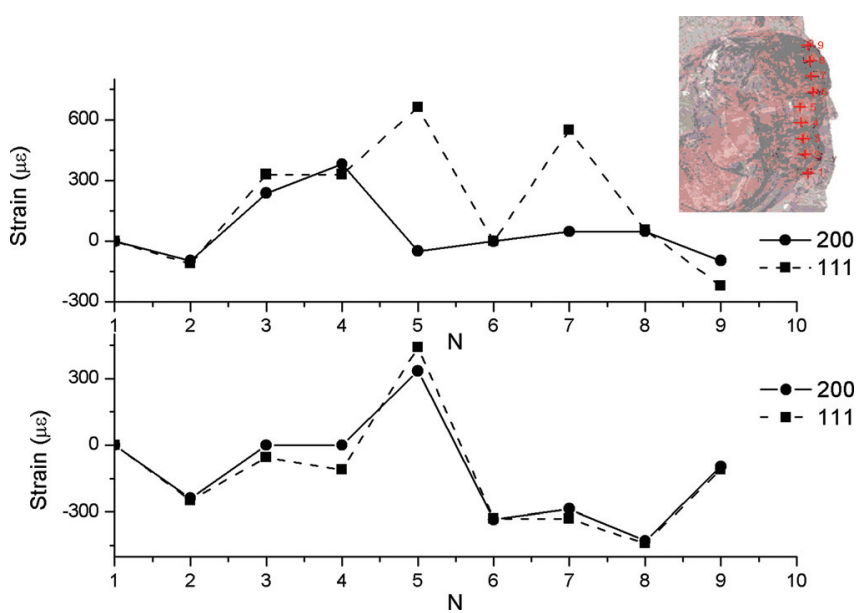

FIG. 12. (Color online) Strain plots of the face and beard region as function of the measurement point index $(\mathrm{N})$ reported in Fig. 9. The strain is defined as $\mu \varepsilon=\left(d-d_{0} / d_{0}\right) \times 10^{-6}$. The (200) and (111) $\alpha$-phase bronze peaks shown from the $\mathrm{Q}_{1}$ (top) and $\mathrm{Q}_{2}$ (bottom) directions along the scan. The reference point is $\mathrm{N}=1$. The error bars are also reported but they are smaller than the symbol size.

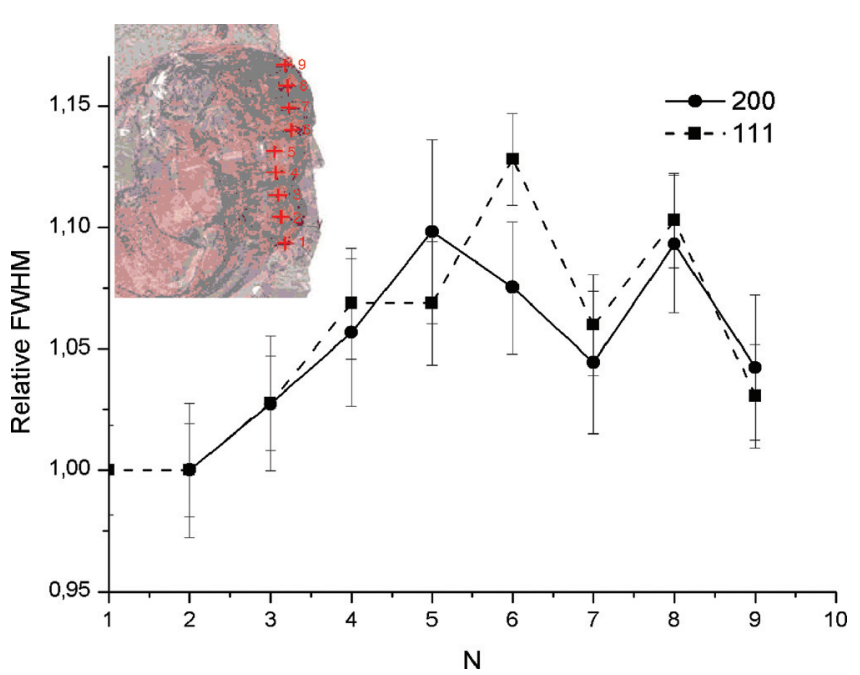

FIG. 13. (Color online) Relative FWHM plots of the face and bear as a function of the number of measurement $(\mathrm{N})$. The (200) and (111) $\alpha$-phase bronze peaks shown from the $\mathrm{Q}_{2}$ direction. FWHMs are normalized to the value of the measurement considered as reference. The reference point is $\mathrm{N}=1$. 
compression. This is related to the fact that this area is part of the re-melting and because it is sub-superficial it was treated by the artist with hand tools to realize the facial features. The 'real discontinuity' generated by the choice of measurement points in the scan between $\mathrm{N}=5$ and $\mathrm{N}=6$ [see Figs. 9(a) and 12] is also present in the strain. The relative FWHM plots reported in Fig. 13 confirmed that the studied zone was highly inhomogeneous.

\section{CONCLUSIONS}

Nondestructive neutron diffraction measurements were performed on a 15th Century Florentine Renaissance art masterpiece. The technique provided valuable and useful information about the history of a gilded bronze sculpture depicting a head on a cylinder-shaped base, presenting a second melting and thus a re-melting area.

A first set of measurements was performed on a portion of the artifact to analyze differences in the position and shape of the diffraction peaks within the first and second melting. These result demonstrated the presence of a dendritic segregation of the bronze alloy in the re-melting area which is typical of an as-cast alloy with higher cooling rates. This may suggest that the re-melting was only a filler material without any particular treatment. Primary melting, on the contrary, showed the sign of heat treatments such as annealing and re-crystallization which are indicative of a homogenization process.

Additionally, a suspected cavity or inhomogeneous zone inside the head created during the second melting was investigated. In fact, neutron radiography studies had shown a region of low neutron attenuation. The results suggest that such a volume is hollow thus excluding the presence of fusion clays. This volume is located in the area from the base of the neck to the occipital lobe.

A set of measurements was also devoted to the study of the bronze peak-broadening and its strain trends. Results showed that near the base, the primary fusion is extended only $7 \mathrm{~mm}$ under the gilding. Strain analysis additionally revealed a similar trend in re-melting and primary fusion: along the axis of the cylinder-shaped base a widening of crystal planes is present while along the radius a compression of the plains is present. Widening and compression have the same magnitude. The re-melting scans have a larger strain variation which can be related to the absence of a homogenization process.

Additionally a relative FWHM study demonstrated differences in treatments: re-melting is only a cast while the primary melting has some homogenization treatments.

Finally it was demonstrated that the face and beard region were part of the second melting. Re-melting seems to have been realized by the artist to give thickness to the relief and make it much more hard-wearing.

This study shows that neutron diffraction investigation provides unique and valuable information about the manufacturing process of historically relevant artifacts.

\section{ACKNOWLEDGMENTS}

The authors wish to thank the Opera Santa Maria Del Fiore and Soprintendenza Speciale per il patrimonio Storico, Artistico, Etnoantropologico e per il Polo Museale della città di Firenze for having made the analysis on the Ghiberti's relief possible. This work was performed under the agreement in force between the Ministero per i Beni e le Attività Culturali (MIBAC), the Università degli Studi di Roma 'Tor Vergata' and Università degli Studi Milano-Bicocca 2007 for neutron spectroscopy. Special thanks to the MIBAC team: Dr. A.P. Recchia, Dr. R. Binacchi, Dr. S. Celentino, and Dr. M.T. Didedda.

Experiments at the ISIS Pulsed Neutron and Muon Source were supported by a beamtime allocation from the Science and Technology Facilities Council. The authors acknowledge Consiglio Nazionale delle Ricerche (CNRItaly) for financial support, within the agreement CNRCCLRC ISIS and ISIS sample environment team.

Work performed with financial support by the European Community "New and Emerging Science and Technology" (Contract No. 15311).

${ }^{1}$ E. Mello, P. Parrini, M. Matteini, A. Moles, G. Rocchi, A. Bartolozzi, L. Giorgi and G. Giusgredi. Lorenzo Ghiberti. Storie di Giuseppe e di Beniamino, storie di Adamo ed Eva. -Stories of Joseph and Benjamin, stories of Adam and Eve. Metodo e Scienza - operativa ricerca nel restauro (Method and Science - operative research in the restoration), Sansoni Editore. 168-202 (1982).

${ }^{2}$ P. Fiorentino, M. Marabelli, M. Matteini, and A. Moles, Studies in Conservation 27, 145 (1982).

${ }^{3}$ E. Mello, Gold Bull. 19(4), 123 (1986).

${ }^{4}$ S. Siano, M. Miccio, P. Bertelli, F. Marinelli, S. Mugnaini and G. Garagnani. Studio sulla tecnica di fusione dei rilievi della Porta del Paradiso - Study of the fusion technique of Gate of Paradise relief. Schede di restauro - restoration schedule.

${ }^{5}$ S. Siano, L. Bartoli, J. R. Santisteban, W. Kocjkelmann, M. R. Daymond, M. Miccio, and G. De Marinis, Archaeometry 48, 77 (2006).

${ }^{6}$ L. Bartoli, S. Siano, W. Kockelmann, J. Santisteban, M. Miccio and G. De Marinis, Nuovo Cimento 30, 1 (2007).

${ }^{7}$ G. Festa, C. Andreani, M. P. De Pascale, R. Senesi, G. Vitali, S. Porcinai, A. M. Giusti, R. Schulze, L. Canella, P. Kudejova, M. Mühlbauer, B. Schillinger, and the Ancient Charm Collaboration, J Appl. Phys. 106, 4 (2009).

${ }^{8}$ G. Festa, W. Kockelmann, A. Kirfel, and the Ancient Charm Collaboration, Neutron Diffraction Analysis of 'Black Boxes'Archeometry workshop, Hungary, January 2008.

${ }^{9}$ W. Kockelmann, S. Siano, L. Bartoli, D. Visser, P. Hallebeek, R. Traum, R. Linke, M. Schreiner, and A. Kirfel, Appl. Phys. A 83, 175 (2006).

${ }^{10}$ H. Postma, L. Amkreutz, A. Borella, M. Clarijs, H. Kamermans, W. Kockelmann, A. Paradowska, P. Schillebeecks, D. Visser, J. Radioanal. Nucl. Chem. 283, 3 (2010).

${ }^{11}$ J. R. Santisteban, M. R. Daymond, J. A. James, and L. Edwards, J Appl Cryst. 39, 812 (2006).

${ }^{12}$ J. A. Dann, M. R. Daymond, J. A. J. James, J. R. Santisteban, L. Edwards. Proc. ICANS-XVI, Düsseldorf-Neuss, Germany (2003).

${ }^{13}$ J. A. James and L. Edwards, Nucl. Instrum. Methods. Phys. Res. A 571, 709 (2007).

${ }^{14}$ A. C. Larsonand R. B. von Dreele, General structure analysis system. Los Alamos National Laboratory Report LAUR. 86-748, 2004.

${ }^{15}$ S. Siano, L. Bartoli, J. R. Santisteban, W. Kockelmann, M. R. Daymond, M. Miccio, and G. De Marinis, Archaeometry 48, 77 (2006). 